\title{
Pengembangan Aplikasi Permainan self-confidence Book Untuk Meningkatkan self-confidence Pada Anak Tunagrahita
}

\author{
Citra Nofita Nur Amalia ${ }^{1}$, Devira Putri Giana ${ }^{2}$ \\ ${ }^{12}$ Universitas Negeri Surabaya, Indonesia \\ Email: citraamalia0106@gmail.com
}

\section{INFORMASI ARTIKEL}

Terkirim 12-Mei-2020

Revisi 18-Juni-2020

Diterima 29-Nov-2020

\section{Kata kunci:}

Tunagrahita, Permainan Self

Confidence Book

\begin{abstract}
ABSTRAK
Tujuan dari penelitian ini adalah untuk meningkatkan self-confidence pada anak tunagrahita yang dirancang menggunakan permainan selfconfidence book berbasis aplikasi sehingga memberikan daya Tarik pada anak tunagrahita. Metode yang digunakan dalam penelitian ini yaitu studi literatur dengan menelaah 8 jurnal terkait permainan selfconfidence book (busy book). Hasil litelatur yang telah di riview digunakan untuk mengembangkan penelitian ini terkait permainan self confidence book berbasis aplikasi untuk anak tunagrahita. Hasil penelitian menunjukkan dari 30 anak tunagrahita kelompok intervensi sebelum diberikan permainan menunjukkan 16 anak mengalami tidak percaya diri dengan rata-rata 2.13 , sedangkan pada kelompok kontrol menunjukkan 18 anak mengalami tidak percaya diri dengan rata-rata 1.73. Setelah diberikan permainan pada kelompok intervensi menunjukkan 14 anak mengalami percaya diri dengan rata rata 3.20 sedangkan pada kelompok kontrol menunjukkan 17 anak mengalami tidak percaya diri dengan rata-rata 1.70 . Terjadi peningkatan rata-rata kepercayaan diri anak tunagrahita sebelum dan sesudah diberikan permainan dengan rata-rata 2.13 sebelum dilakukan intervensi dan 3.20 setelah diberikan intervensi pada kelompok intervensi.
\end{abstract}

(i) (2) This is an open access article distributed under the Creative Commons 4.0 Attribution License, This license lets others remix, tweak, and build upon your work even for commercial purposes, as long as they credit you and license their new creations under the identical terms @2018 by author and Universitas Negeri even for
Padang.

\section{Pendahuluan}

Sejauh mana seseorang menghargai, memahami, dan percaya pada dirinya sendiri telah lama dianggap sebagai variabel utama yang memengaruhi hubungan interpersonal, pola perilaku, dan tingkat penyesuaian terhadap situasi kehidupan. Orang-orang yang telah berhasil di masa lalu dan yang telah mengalami konsekuensi positif yang sepadan dengan upaya yang telah mereka keluarkan cenderung memiliki harapan yang tinggi untuk kesuksesan di masa depan, keyakinan pada kekuatan mereka sendiri untuk melakukan perubahan, dan tingkat diri yang cukup tinggi -menghargai. Sebaliknya, individu yang tidak mengalami konsekuensi yang bergantung pada usahanya sendiri merasa tidak berdaya dalam kemampuan mereka untuk mengubah lingkungan, memiliki harapan akan kinerja masa depan dan pada umumnya memiliki self confidence yang buruk (Dorothy,1974).

Perilaku merupakan segala sesuatu aktivitas seseorang melakukan sesuatu kegiatan tertentu dan juga apa yang kita sendiri katakan dan kerjakan. Perilaku identik dengan manusia atau subjek, tentu saja perilaku tersebut dapat diamati. Agar dapat teramati, maka perilaku tersebut bersifat perlakuan yang dapat dilakukan dan berupa perkataan yang dapat dikatakan, memiliki dimensi yang dapat diukur, dapat dideskripsikan, dapat mempengaruhi lingkungan, serta beralaku sesuai dengan norma yang berlaku.

Perlakuan yang menunjukka perilaku dapat kita control sesuai dengan situasi dan kondisi diri kita dan lingkungan sekitar. kita dapat menahan dan mengontrol diri kta sesaui dengan kemauan kita. 
Otak dan badan kita juga saling berkolaborasi agar perilaku yang tidak baik itu tidak muncul. Namun berbeda dengan anak berkebutuhan khusus. Mereka tidak mengetahui bagaimana cara mengontrol perilaku mereka yang berlebihan seperti hiperaktif, impulsive, marah-marah tanpa sebab, cemas dan lain sebagainya. Mereka juga tidak tahu bagaimana caranya untuk menunjukkan perilaku rasa percaya diri, rasa tanggung jawab, bahkan untuk menghargai dirinya sendiri. Seperti halnya anak tunagrahita yang memiliki perilaku tidak percaya diri. Karena mereka merasa berbeda dengan yang lain. anak tuna grahita membutuhkan bimbingan dan program khusus untuk meningkatkan rasa percaya diri mereka.

Tunagrahita adalah Tunagrahita adalah individu yang memiliki intelegensi yang signifikan berada dibawah rata-rata dan disertai dengan ketidakmampuan dalam adaptasi perilaku yang muncul masa perkembangan (Meimulyani \& Caryoto, 2013). Selanjutnya menurut (Dorothy,1974) anak keterbelakang mental adalah anak-anak mengalami kegagalan berulang, yang pertama kemungkinan karena kemampuan intelektual yang lebih rendah dan yang kedua karena masalah perilaku atau emosional.

Media quiet book sering juga disebut busy book atau activities book, yaitu media 3 dimensi jenis model atau tiruan berupa buku kain bermaterian flanel yang terdiri dari halaman-halaman yang berisi bermacam kegiatan anak-anak seperti menghitung, mengenal warna, mengikat tali, mengenal satwa, dll yang besifat edukatif.

Amy pincock (2013) menyatakan "Quiet books teach basic skill such as pulling a zipper, tying a bow, and buttoning a button. Children love to feel textures and manipulate objects, and quiet books are perfect for providing these experiences", yang artinya quiet book dapat mengajarkan perilaku selfconfidence pada anak tunagrahita.

\section{Metode}

Metode yang digunakan dalam penelitian ini adalah penelitian studi literatur dengan menelaah 8 artikel jurnal terkait busy book "Self-Confidence Book" pada anak tunagrahita. Hasil dari berbagai riview literatur ini akan digunakan untuk mengembangkan permainan aplikasi "Self-Confidence Book" untuk meningkatkan Self-Confidence pada anak tunagrahita.

\section{Hasil Penelitian dan Pembahasan}

Penelitian dengan menggunakan media busy book sudah banyak dilakukan oleh peneliti, karena dari segi bahan mudah didapat dan mudah untuk dibuat semenarik mungkin sesuai dengan tujuan penelitian. Sehingga banyak peneliti yang berhasil mencapai tujuan yang diharapkan dengaan memodifikasi Busy Book ini.

Dalam penggunaan media busy book banyak memiliki manfaat dan kekurangannya. Dalam segi manfaat yaitu memiliki daya tarik untuk pembelajaran pada anak tunagrahita, modifikasi busy book sesuai dengan apa yang peneliti butuhkan sehingga kita dapat menghias semenarik mungkin agar anak tunagrahita memiliki motivasi belajar yang tinggi, banyak peneliti yang berhasil mencapai tujuan penelitian yang diharapkan. Namun ada juga kerugian dari nusy book ini yaitu bahan yang digunakan mudah rusak sehingga tidak efektif dan tahan lama untuk jangka panjang, tidak ada audio sehingga saat anak berhasil bermain dengan baik reward hanya dari guru.

Beberapa penelitian yang menunjukkan keberhasilan menggunakan busy book untuk anak tunagrahita. Penelitian dari Astrinia, et al (2019) terkait Cognitive Comprehension of Dental Health Education Using a Busy Book "Ayo Sikat Gigi” in Down Syndrome Children. Hasil penelitian 
menunjukkan bahwa Peningkatan skor pemahaman kognitif pada peserta setelah pengujian menunjukkan bahwa permainan Busy Book, Ayo Sikat Gigi, tampaknya menjadi alat pembelajaran yang efektif untuk pendidikan kesehatan gigi pada anak-anak Down Syndrome, temuan menggunakan permainan Busy Book bermanfaat untuk penggunaannya oleh dokter gigi, orang tua, dan guru mengenai pentingnya perawatan kesehatan mulut untuk anak-anak Down Syndrome dan penggunaan mainan pendidikan sebagai alat pembelajaran untuk memberikan kesadaran, pemahaman, dan keterampilan swadaya untuk mencapai kebersihan mulut yang baik.

Selanjutnya penelitian yang dilakukan oleh Yessy, Meidiana, \& Elis (2018) terkait Efek Permainan "My Confident Book" Terhadap Peningkatan Kepercayaan Diri Anak Tunagrahita. Hasil penelitian menunjukkan bahwa (1) Hasil penelitian berdasarkan karakteristik responden pada kelompok intervensi dan kelompok kontrol anak tunagrahita berusia 9-11 tahun sebagian besar berjenis kelamin laki-laki, mayoritas merupakan anak pertama dan pendidikan orang tua yaitu sekolah dasar (SD) $p$-value $>(\alpha=0.05)$. (2) Kepercayaan diri anak tunagrahita sebelum diberikan permainan My Confident Book pada kelompok intervensi anak mengalami tidak percaya diri dengan rata rata 2.13, sedangkan pada kelompok kontrol anak mengalami tidak percaya diri dengan rata rata 1.73. (3) Ada perbedaan kepercayaan diri anak tunagrahita pada kelompok intervensi dan pada kelompok kontrol. (4) Ada pengaruh penggunaan permainan My Confident Book terhadap kepercayaan diri siswa pada kelompok intervensi.

Selanjutnya penelitian yang dilakukan oleh Nova Putri Pangesti, Siti Wahyuningsih, \& Nurul Kusuma Dewi (2019) terkait Peningkatan Kemampuan Motorik Halus Anak Usia 4-5 Tahun Melalui Media Busy Book. Hasil dari penelitian tersebut menunjukkan bahwa Berdasar dari hasil penelitian yang telah dilaksanakan, setelah adanya tindakan yaitu penerapan melalui media busy book terdapat peningkatan terhadap kemampuan motorik halus anak. Peningkatan kegiatan dalam indikator koordinasi mata dan tangan untuk melakukan gerakan rumit berupa menali, mengancingkan kancing, dan menempel pola potongan gambar maka setiap kegiatan dalam indikator pada setiap siklus tersebut mengalami peningkatan yang cukup signifikan terkait kemampuan motorik halus anak.

Berdasarkan pemaparan hasil artikel penelitian diatas terkait Busy Book untuk anak tunagrahita yaitu memudahkan untuk belajar, menumbuhkan rasa percara diri, mengingkatkat kemandirian. Media busy book ini memiliki kelebihan yaitu materi yang dipakai sesuai dengan materi yang akan dicapai, sehingga guru, orangtua, terapi bebas untuk memodivikasi semenarik mungkin, membantu anak untuk menumbuhkan rasa semangat dalam belajar karena sangat menarik. Sedangkan kekurangan dari game Busy Book ini adalah bahan yang digunakan mudah rusak sehingga tidak bisa digunakan jangka panjang, tidak ada audio yang menyertai permainan Busy Book.

\section{Kesimpulan}

Dari hasil review penelitian diatas, penelitian ini merekomendasi untuk mengembangkan permainan aplikasi Self-Confidence Book untuk meningkatkan kemampuan Self-Confidence pada anak tunagrahita. Sehingga dengan adanya pengembangan permainan ini berbasis aplikasi akan menambah ketertarikan pada anak tunagrahita, permainan yang disediakan akan lebih banyak sehingga menambah rasa percaya diri anak, terdapat audio yang menyertai permainan, dengan dikemas dalam bentuk aplikasi akan mempermudah guru, terapi , bahkan orangtua untuk melatih rasa percaya diri anak tunagrahita. 


\section{Daftar Rujukan}

A.Moreena, and Alam J.1974. Self-Concept in Educable Mentally Retarded and Emotionally Handicapped Children. Journal Of Abnormal Child Psychology.Vol 2 No.4.

Aulia, R. Irma, A. 2017. Strategi Komunikasi Interpersonal Orang Tua dan Anak Dalam Meningkatkan Rasa Percaya Diri Anak Penyandang Disabilitas (Interpersonal Comunication Strategy Used by Parents in Enhancing Self- Confidence of Disabled Children). Jurnal Ilmiah Mahasiswa FISIP Unsyiah Volume 1, Nomor 1

Pangesti Putri, Nurul, \& Siti. 2019. Peningkatan Kemampuan Motorik Halus Anak Usia 4-5 Tahun Melalui Media Busy Book. Jurnal Kumara Cendekia.Vol 7 no.4

Pincock. A. 2013. Quiet Book Patterns : 25 Easy To Make Activities For Your Children(CD Included). Cedar fort: springvile UT

Ramadhan Samik, dan Sudarsini.2018. Media Quiet Book dalam Meningkatkan Keterampilan Memakai Baju Berkancing Bagi Tunagrahita. Jurnal Ortopedagogia.Vol 4 no.1

Ristia Putri, et al.2019. Cognitive Comprehension of Dental Health Education Using a Busy Book "Ayo Sikat Gigi" in Down Syndrome Children. Journal of International Dental and Medical Research. Vol 12 No 2.

Sari Gema, Abdul, \& Usep.2019. Media Quiet Book untuk Meningkatkan Keterampilan Merawat Luka Ringan Anak Tunagrahita. Jurnal Ortopedagogia. Vol 5 no.2

Sudarsini, Ramadhani N.S. 2018. Media Quiet Book dalam Meningkatkan Keterampilan Memakai Baju Berkancing Bagi Tunagrahita. Jurnal Ortopedagogia. Vol 4 No.1

Widodo, Median, \& Elis. 2018. Efek Permainan "My Confident Book" Terhadap Peningkatan Kepercayaan Diri Anak Tunagrahita. Jurnal Universitas Diponegoro.

Yulita Odelia. 2019. Sentence Patterns And Moods In Cooking, And Activity Instruction In Kuffner's the Children's Busy Book. Jurnal Pendidikan Khusus. Vol 8 No.3 